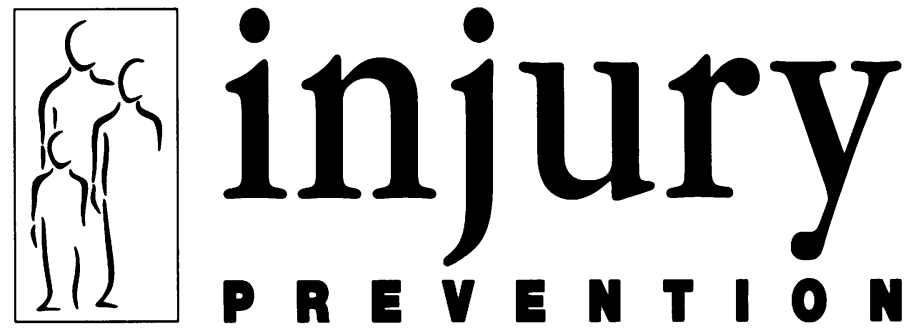

Journal of the International Society for Child and Adolescent Injury Prevention

\title{
Editorials
}

\section{Tales of contrasting strategies}

The contents of this issue present two sharply contrasting perspectives on injury control. Each provides rich food for thought for most readers.

On the one hand, the two papers in the Injury Classics section describe a success story that is almost too good to be true. (In fact, as you will see, the solution reported in the second paper, circa 1977, may not be as good or as widely applicable as was first anticipated when viewed in the light of 1995 realities.)

On the other hand, the three papers describing what primary care physicians and nurses in England and France are doing with respect to injury prevention counselling is a state-of-the-art report on what might be characterised as a 'good-news, bad-news' situation.

In brief, the 'falls from heights' tale presents a picture of a relationship between basic research and a proven solution, all occurring within a relatively short time span - six years. The essence of the solution as presented here is a mixture of regulatory action and community involvement. The first of the papers, that of Bergner, Mayer, and Harris, published in 1971, is typical of the kind of research conducted when a new problem is suspected. Although it was obviously appreciated before this study that children were injured when falling from heights, what Bergner and his colleagues did was to document the nature and extent of these events. In effect, this study put the issue 'on the map' and thus legitimized further scientific inquiry. Remember, as you read it, that it represents work done over one quarter of a century ago, using tools much more primitive than those available today. Yet the findings are clear and persuasive; few could leave this report without being convinced that these falls were a serious problem and that a solution was urgently needed.

Then, in almost poetic symmetry, an answer was provided by workers in the same department in the same city several years later. Charlotte Spiegel and Francis Lindaman took up the challenge and developed a solution that was both logical and imaginative. In the 1970s prevention strategies that did not rely almost exclusively on health education were extremely rare. Nevertheless, Spiegel and Lindaman chose a regulatory solution and scientifically demonstrated that requiring window guards to be installed in high rise buildings occupied by children, actually saved lives.
This link between identifying a problem and reaching a fairly immediate, well evaluated solution, is rare in any branch of science. It is unusual, to say the least, for a solution to be found so soon after the identification of a problem, and even more astounding for the solution to actually be applied! Possibly part of the explanation for the success in this instance lay in the close relationship between the key actors at each stage.

In contrast, the message embodied in the papers from Carter, Kendrick, and Lévêque and their colleagues, is another tale entirely. Their stories are somewhat analogous to part I of the falls epic, in the sense that together they clearly define a problem. Rather than being the discovery of a cause of injury morbidity or mortality, in this instance the problem relates to the delivery of what is assumed to be an efficacious preventive measure - parent counselling. The thread running through this story is that in none of the situations described is there good evidence of widespread interest or involvement of physicians or nurses in the counselling activity. Or, rather, to state my interpretation more accurately, while there is reasonable evidence of interest there is much less of the actual involvement of these health professionals in this activity.

Moreover, none of these papers provide a clear solution to this lack of involvement, assuming, of course, that it is widely agreed that more such counselling is required. Although I may be personally sceptical of the value of parent education as a tool in injury prevention, it would be senseless to suggest that it is undesirable. It is logical to assume that no matter how well or badly it is done, the net result of such counselling may help in some way. Further, Bass, in his Opinion column, suggests that the basis for a belief in the efficacy of counselling is well established. Despite the understandable scepticism raised by Klassen in his dissenting opinion, based on the quality of evidence, when all is said and done it is likely we will agree that there is good reason to want physicians and nurses to provide more such counselling. It is especially likely to be justified when performed during infancy and the preschool years, when contacts with these children are frequent and many mothers are new to child raising.

So, in summary, we have examples from what sometimes appears to be two opposing ideological camps: one favouring regulatory solutions and the other favouring education 
or counselling. Perhaps editors should not take sides. In any event it seems prudent to declare a bias when one exists. In this case I am far more convinced of the benefits of regulations such as those requiring the installation of window guards, than I am of the benefits of counselling or education. But, fortunately, this bias is not an issue because there is no need to make a choice between the two. The ideal solution is to have them work together to flourish side-by-side. And notably, the 'Children Can't Fly' programme included an educational component as well as an element of community involvement.

Much more important than struggling with such arbitrary choices, however, is finding ways to ensure that each modality, counselling and regulation, is able to work more effectively and efficiently. For advocates of window guards to prevent the tragedy of children falling from heights, the main barrier (no pun intended) in many cities (certainly in the US) is the understandable concern of fire departments that certain types of guards may prevent escape. Although Charlotte Spiegel has reviewed the circumstances of the deaths of all children in New York city in high rise buildings after fires, and concluded that in no instance was a window guard responsible for the death, this message has either not been heard or is not believed by fire departments in other cities. (I'm curious to learn what the situation is in
Europe, Australasia, and elsewhere regarding this dilemma.) But at least in this case the solution has progressed to a point where all that remains is overcoming this obstacle and then persuading all municipalities that window guard regulation is a vital step to preventing these tragic falls.

In the case of the counselling issue, however, much more needs to be done to improve the techniques and conditions of delivery. A future issue will include a paper revealing the differences between what parents perceive they are told in counselling sessions with physicians, and what physicians believe they have done. We need more such studies to enhance the skills of counsellors. This is not an activity all health professionals are trained to do and thus few do it well. Additionally, there is little incentive to enhance this skill because it is not always (or often) reimbursed under fee-for-service arrangements. Hence, a cynical view is that many impediments to more and better counselling would be removed if more countries followed the example of some and properly reimbursed physicians and nurses for such services. Until such time, however, counselling on any preventive topic is almost certain to remain the 'ugly duckling' in the health professionals' repertoire.

\section{Another contest}

Editors tend to be partial to papers with catchy, clever titles, and experienced authors know the value of such titles. In our field, three of my all time favourites are 'Children Can't Fly', one of the papers in this issue; 'Save the Trees' (a paper about skiing injuries); and 'Flame- resistant sleepwear: have the bird-watchers gone ape?' If you will send me your favourite I will list it and periodically poll readers to see how it ranks alongside the others submitted. If yours is ranked first you will be suitably rewarded.

\section{Work for readers}

While on the subject of material desired from readers, I also seek photos suitable for publication (either of an injured child or a dangerous situation - if the former we would require signed consent to publish); appropriate cartoons (we will chase after the consent); and, most importantly, contributions describing programmes that your group or another in your community is conducting to prevent injuries. If possible, details about the sources of funding, staffing, how the work is actually being done, etc, would be appreciated. 